\title{
Impact of white matter changes on neurologic outcomes of total arch replacement using antegrade cerebral perfusion
}

Yuki Ikeno, MD, ${ }^{\mathrm{a}}$ Koji Sasaki, MD, ${ }^{\mathrm{b}}$ Takashi Matsueda, MD, ${ }^{\mathrm{a}}$ Takeshi Inoue, MD, ${ }^{\mathrm{a}}$ Hiroshi Tanaka, MD, PhD, ${ }^{a}$ Koji Sugimoto, MD, PhD, ${ }^{b}$ and Yutaka Okita, MD, $\mathrm{PhD}^{\mathrm{a}}$

ABSTRACT

Objective: To evaluate the impact of white matter changes on neurologic outcomes after total arch replacement using antegrade cerebral perfusion.

Methods: White matter changes were assessed using a visual Fazekas scale on preoperative magnetic resonance images. From October 1999 to December 2016, 359 patients who had demonstrated changes on preoperative magnetic resonance imaging underwent elective total arch replacement using antegrade cerebral perfusion. Patients were classified into 3 severity groups: mild (100 patients), moderate (158 patients), and severe (101 patients). Mean follow-up time was $4.8 \pm 3.6$ years. Multivariate logistic regression methods were used to evaluate for an independent association between white matter changes and postoperative neurological outcomes.

Results: Hospital mortality was $2.8 \%$ (10/359), and no significant differences were found across the 3 groups $(P=.604)$. Multivariate analysis demonstrated that the severity of white matter change was significantly associated with both postoperative permanent neurologic deficit (odds ratio, 5.77; 95\% confidence interval, 1.58-38.4, $P=.005$ ) and transient neurologic deficit (odds ratio, 2.46; 95\% confidence interval, 1.45-4.37, $P<.001)$.

Conclusions: White matter changes, defined using the visual Fazekas scale on preoperative magnetic resonance imaging, were significantly associated with significant postoperative adverse neurologic outcomes after total arch replacement using antegrade cerebral perfusion. (J Thorac Cardiovasc Surg 2019;157:1350-7)

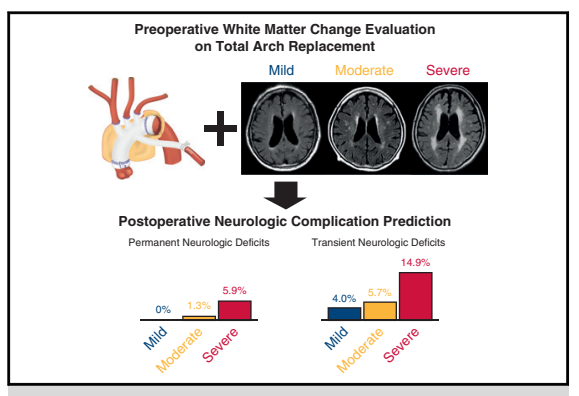

Severe WMCs assessed by Fazekas visual scale on preoperative MRI.

\section{Central Message}

White matter changes on preoperative magnetic resonance imaging are associated with adverse postoperative neurologic outcomes after total arch replacement using antegrade cerebral perfusion.

\section{Perspective}

Cerebral white matter changes, defined by the Fazekas visual scale on preoperative magnetic resonance imaging, are significantly associated with adverse postoperative neurologic outcomes after total arch replacement using antegrade selective cerebral perfusion.

See Commentary page 1358 .
The development of brain-protection methods, particularly antegrade selective cerebral perfusion (ACP), has made a significant contribution to the improvement of surgical outcomes of total arch replacement over the past decade. ${ }^{1,2}$ ACP is now considered to be the most reliable and widely used method. ${ }^{3,4}$ In addition, thoracic endovascular aortic

From the Departments of ${ }^{\mathrm{a}}$ Cardiovascular Surgery and ${ }^{\mathrm{b}}$ Radiology, Kobe University, Kobe, Japan.

Read at The American Association for Thoracic Surgery Aortic Symposium 2018, New York, New York, April 26-27, 2018.

Received for publication March 28, 2018; revisions received Sept 22, 2018; accepted for publication Oct 16, 2018; available ahead of print Jan 14, 2019.

Address for reprints: Yutaka Okita, MD, PhD, Division of Cardiovascular Surgery, Department of Surgery, Kobe University Graduate School of Medicine, 7-5-2 Kusunoki-cho Chuo-ku, Kobe 650-0017, Japan (E-mail: yutakaokita@ gmail.com). $0022-5223 / \$ 36.00$

Copyright (c) 2018 by The American Association for Thoracic Surgery

https://doi.org/10.1016/j.jtcvs.2018.10.150 repair has emerged as an attractive alternative for treating aortic arch aneurysms, especially in high-risk patients.' However, with either procedure, perioperative brain damage resulting in stroke or transient neurologic dysfunction remains a major source of mortality and morbidity.

Age-related cerebrovascular white matter changes (WMCs) frequently are observed in elderly patients and are considered evidence of small-vessel disease. In

Scanning this QR code will take
you to the article title page to
access supplementary informa-
tion. To view the AATS Aortic
Symposium Webcast, see the
URL next to the webcast
thumbnail.



Abbreviations and Acronyms
$\mathrm{ACP}=$ antegrade selective cerebral perfusion
$\mathrm{CI}=$ confidence interval
$\mathrm{CPB}=$ cardiopulmonary bypass
FLAIR $=$ fluid-attenuated inversion recovery
MRA = magnetic resonance angiography
MRI = magnetic resonance imaging
$\mathrm{OR}=$ odds ratio
PND = permanent neurologic deficit
$\mathrm{TND}=$ transient neurologic deficit
$\mathrm{WMC}=$ white matter change

experimental models, WMCs have been induced by chronic cerebral hypoperfusion, which was associated with proliferating activated microglia and astroglia. ${ }^{6}$ Recent advances in magnetic resonance imaging (MRI) have demonstrated that WMCs are independently associated with cognitive decline and dementia, which are central components of frailty.,

Since the late 1980s, several grading methods for WMC have been proposed. Our earlier studies reported that WMC, defined according to the Scheltens scale, ${ }^{9}$ significantly predicted adverse neurologic outcomes. ${ }^{10,11}$ However, the complexity of analysis proved problematic in clinical application (Figure E1). In contrast, the Fazekas visual scale $^{12-15}$ is the oldest and the most extensively used assessment tool and is simple and useful for preoperative risk stratification. ${ }^{13-15}$

In this study, adding the more than 5-year follow-up results of a previous cohort and our current surgical candidates, we evaluated the impact of WMC graded according to the Fazekas visual scale on neurologic outcomes after elective total arch replacement using ACP.

\section{MATERIALS AND METHODS \\ Study Population}

From October 1999 to December 2016, 409 patients underwent elective total arch replacement using ACP at our institution. Fifty patients, in whom preoperative MRI assessment was not performed, were excluded. Three hundred fifty-nine patients were eventually enrolled in this study.

Follow-up data were obtained by clinical visit, telephone, or written correspondence and were available for all but 7 patients $(1.9 \%)$, who were lost within 1 year after the operation. The mean follow-up period was $4.8 \pm 3.6$ years (range 0-15.7 years). This study protocol was reviewed and approved by the institutional review board. An informed consent waiver was granted.

\section{Image Analysis}

Our MRI assessment protocol has been reported previously. ${ }^{11}$ In brief, MRI of the brain was performed using a 1.5-T scanner, consisting of axial T1-weighted, T2-weighted, and fast fluid- attenuated inversion recovery (FLAIR), as well as coronal FLAIR imaging. The intracranial and extracranial vasculatures were evaluated preoperatively using magnetic resonance angiography (MRA). All patients underwent routine 2-dimensional timeof-flight MRA through the neck and 3-dimensional time of flight MRA through the circle of Willis. Carotid stenosis was defined as more than $50 \%$ stenosis.

On the FLAIR images, we applied the Fazekas visual scales to rate the severity of age-related WMC. Patients were classified into 3 severity groups according to this scale (Figure 1$)^{13-15}$ :

Grade 1 (mild changes): single lesions $<10 \mathrm{~mm}$ and/or areas of "grouped" lesions $<20 \mathrm{~mm}$ in any diameter.

Grade 2 (moderate changes): single hyperintense lesions, 10 to $20 \mathrm{~mm}$ in size, and hyperintense areas linked by no more than "connecting bridges" $>20 \mathrm{~mm}$ in any diameter.

Grade 3 (severe changes): both single and confluent hyperintense areas of $\geq 20 \mathrm{~mm}$ in any diameter.

To minimize the error of each analyzer, 2 trained observers (cardiothoracic surgeon Y.I. and radiologist K.S.) performed all WMC measurements. The inter-rater $\kappa$ was 0.65 for each rating and 0.86 for detecting severe WMC.

\section{Definition of Neurologic Outcomes}

Permanent neurologic deficits (PNDs) were defined as the presence of deficits that persisted at hospital discharge. Transient neurologic deficits (TNDs) were defined as delayed awaking, transient loss of orientation, slurred language, agitation, poor response to comments, and transient hemiparesis that had disappeared by hospital discharge. Intraoperative cerebral infarction or ischemia was diagnosed by a neurologist, using diffusionweighted MRI or computed tomography of the brain, when patients had any symptoms related to TNDs or PNDs. Seven patients who had postoperative stroke in their rehabilitation course were defined as neither TNDs nor PNDs.

\section{Surgical Approach}

All 359 patients underwent total arch replacement through median sternotomy. The surgical strategies described in our previous series. ${ }^{3,16}$ To summarize, we have used ACP with 3 cannulae for each arch vessel as brain protection, with minimal tympanic temperatures between $20^{\circ} \mathrm{C}$ and $23^{\circ} \mathrm{C}$ and minimal rectal temperatures below $30^{\circ} \mathrm{C}$. In addition, we tried to take longer cooling time in patients with severe WMC. The ACP flow was maintained at 10 to $12 \mathrm{~mL} / \mathrm{kg} / \mathrm{min}$ using an independent roller pump, and the cannula tip pressure was maintained between 30 and $40 \mathrm{~mm} \mathrm{Hg}$. After performing the distal anastomosis, we started antegrade perfusion of the lower body and rewarming. Subsequently, proximal anastomosis was performed, followed by coronary reperfusion. Finally, the aortic arch vessels were reconstructed individually.

\section{Statistical Analysis}

All continuous variables were expressed as the mean $\pm \mathrm{SD}$, and categorical variables are expressed as the number (\%) of patients. The clinical characteristics were compared among groups using the $\chi^{2}$ test for categorical variables. Assumption of normality of continuous data was tested with the Shapiro-Wilk test. If the assumption of normality was met, continuous variables were compared using the Student $t$ test. The Mann-Whitney $U$ test was used for nonparametric variables. Linear trends in the variables across 3 groups were assessed using the Cochran-Armitage test for categorical variables and the Jonckheere-Terpstra test for continuous variables. $P$ values $<.05$ were considered statistically significant. $P$ values $<.05$ in the univariate analysis were used to identify variables for the multivariate regression analysis for PNDs and TNDs. All data analyses were performed with JMP 11.0 software (SAS Institute, Cary, NC), except for the Jonckheere-Terpstra test, which was executed in EZR, which is a graphical user interface for $\mathrm{R}$ (version 3.1.2; The $\mathrm{R}$ foundation for Statistical Computing, Vienna, Austria). 


\section{RESULTS}

According to the severity of WMC, 359 patients were subdivided into 3 groups; mild ( $\mathrm{n}=100$ patients, $27.9 \%$ ), moderate $(\mathrm{n}=158$ patients, $44.0 \%)$, and severe $(\mathrm{n}=101$ patients, $28.1 \%$ ). Preoperative patient characteristics are shown in Table 1. Patients with more severe WMC tended to be older in age $(P<.001)$ and presented with more comorbidities. They also had lower body mass index $(P=.006)$ and estimated glomerular filtration rate $(P<.001)$. There was a significantly greater prevalence of ischemic heart disease $(P<.001)$, carotid artery stenosis $(P=.014)$, neurologic dysfunction (preoperative monoplegia and hemiplegia due to old stroke) $(P=.005)$, and previous stroke $(P<.001)$ found in patients with more severe WMCs. Prevalence of intracranial artery stenosis and incomplete circle of Willis was similar across the 3 groups. The European System for Cardiac Operative Risk Evaluation II and Japan score for 30-day mortality increased significantly with more severe WMC grades.

Intraoperative data are shown in Table 2. Minimal tympanic temperature was significantly lower, and ACP time was significantly longer, in patients with more severe WMCs. Cardiopulmonary bypass (CPB) time and concomitant procedures, including coronary artery bypass grafting, were similar across groups.

\section{Early Outcomes}

The 30-day mortality and in-hospital mortality were $1.4 \%$ (5/359 patients) and 2.8\% (10/359 patients), respectively. Cause of early death included bowel necrosis $(n=2)$, hemorrhagic stroke $(\mathrm{n}=1)$, pulmonary hemorrhage $(\mathrm{n}=1)$, multisystem organ failure $(n=1)$, sepsis $(n=1)$, bowel perforation $(\mathrm{n}=1)$, pancreatitis $(\mathrm{n}=1)$, and pneumonia $(\mathrm{n}=2)$. The severity of WMC did not affect the early mortality; however, the 1-year mortality was significantly greater with increased WMC severity (mild: $5.1 \%$, moderate: $5.4 \%$, and severe: $14.7 \% ; P=.014$ ). In regard to postoperative neurologic complications, the overall incidence of PNDs and TNDs was $2.2 \%$ and $7.8 \%$, respectively. The incidence also increased significantly with increasing WMC severity (PNDs; mild: $0 \%$, moderate: $1.3 \%$, and severe: $5.9 \%, P=.004$; TNDs; mild: $4.0 \%$, moderate:

TABLE 1. Patient characteristics

\begin{tabular}{|c|c|c|c|c|c|}
\hline Variables & $\begin{array}{c}\text { Overall } \\
(n=359)\end{array}$ & $\begin{array}{l}\text { WMC mild } \\
(\mathbf{n}=\mathbf{1 0 0})\end{array}$ & $\begin{array}{l}\text { WMC moderate } \\
\qquad(\mathbf{n}=\mathbf{1 5 8})\end{array}$ & $\begin{array}{l}\text { WMC severe } \\
\quad(\mathbf{n}=\mathbf{1 0 1})\end{array}$ & $\begin{array}{l}P \text { value } \\
\text { (trend) }\end{array}$ \\
\hline Age, y & $72.5 \pm 9.7$ & $66.6 \pm 13.4$ & $74.0 \pm 6.4$ & $76.1 \pm 6.8$ & $<.001 *$ \\
\hline Female & 85 (23.7) & $21(21.0)$ & $32(20.3)$ & $32(31.7)$ & .074 \\
\hline BMI, $\mathrm{kg} / \mathrm{m}^{2}$ & $23.4 \pm 3.2$ & $24.0 \pm 3.5$ & $23.4 \pm 3.1$ & $22.9 \pm 3.1$ & $.006^{*}$ \\
\hline Hypertension & $316(88.0)$ & $87(87.0)$ & $138(87.3)$ & $91(90.1)$ & .498 \\
\hline Dyslipidemia & $142(39.6)$ & $41(41.0)$ & $59(37.3)$ & $42(41.6)$ & .931 \\
\hline Diabetes mellitus & $55(15.3)$ & $18(18.0)$ & $24(15.2)$ & $13(12.9)$ & .313 \\
\hline Smoking & $263(73.9)$ & $70(70.0)$ & $119(76.8)$ & $74(73.3)$ & .601 \\
\hline Chronic dissection & 63 (17.6) & $24(24.0)$ & $25(15.8)$ & $14(13.9)$ & .059 \\
\hline Previous aortic surgery & $77(21.5)$ & $23(23.0)$ & $33(20.1)$ & $21(20.8)$ & .704 \\
\hline Preoperative AF & $32(8.9)$ & $5(5.0)$ & $17(10.8)$ & $10(9.9)$ & .224 \\
\hline Chronic lung disease & 117 (32.6) & $33(33.0)$ & $46(29.1)$ & $38(37.6)$ & .482 \\
\hline $\mathrm{eGFR}, \mathrm{mL} / \mathrm{min} / 1.73 \mathrm{~m}^{2}$ & $55.6 \pm 20.5$ & $63.8 \pm 20.3$ & $54.5 \pm 20.6$ & $49.1 \pm 17.6$ & $<.001 *$ \\
\hline Atherothrombotic aorta & $38(11.4)$ & $7(7.3)$ & $22(15.1)$ & $9(9.4)$ & .648 \\
\hline Ischemic heart disease & $124(34.5)$ & $21(21.0)$ & $59(37.3)$ & $44(43.6)$ & $<.001 *$ \\
\hline Carotid artery stenosis & $48(13.4)$ & $7(7.0)$ & $22(13.9)$ & $19(18.8)$ & $.014^{*}$ \\
\hline Intracranial artery stenosis & $33(9.2)$ & $8(8.0)$ & $11(7.0)$ & $14(13.9)$ & .149 \\
\hline Incomplete circle of Willis & $108(30.1)$ & $32(32.0)$ & $51(32.3)$ & $25(24.8)$ & .262 \\
\hline Neurologic dysfunction $\dagger$ & $15(4.2)$ & $2(2.0)$ & $3(1.9)$ & $10(9.9)$ & $.005^{*}$ \\
\hline Previous stroke & $113(31.5)$ & $12(12.0)$ & $52(32.9)$ & $49(48.5)$ & $<.001 *$ \\
\hline EuroSCORE II, \% & $4.9 \pm 4.1$ & $3.6 \pm 2.6$ & $5.1 \pm 4.4$ & $5.9 \pm 4.4$ & $<.001^{*}$ \\
\hline Japan score, 30-d mortality, \% & $6.4 \pm 5.5$ & $5.0 \pm 3.8$ & $6.4 \pm 5.1$ & $7.8 \pm 7.0$ & $<.001 *$ \\
\hline Japan score, $30-\mathrm{d}$ mortality + complications, $\%$ & $25.4 \pm 12.4$ & $21.9 \pm 10.3$ & $25.5 \pm 12.3$ & $28.5 \pm 13.6$ & $<.001^{*}$ \\
\hline
\end{tabular}

The $P$ values are for linear trend across the groups that were stratified by severity of WMCs. WMCs, White matter changes; $B M I$, body mass index; $A F$, atrial fibrillation; eGFR, estimated glomerular filtration rate; EuroSCORE II, European System for Cardiac Operative Risk Evaluation II. $* P<.05$. $\dagger$ Neurologic dysfunction defined as preoperative monoplegia and hemiplegia due to old stroke. 
TABLE 2. Operative data and postoperative complications

\begin{tabular}{|c|c|c|c|c|c|}
\hline Variables & $\begin{array}{c}\text { Overall } \\
(n=359)\end{array}$ & $\begin{array}{l}\text { WMC mild } \\
(\mathbf{n}=\mathbf{1 0 0})\end{array}$ & $\begin{array}{l}\text { WMC moderate } \\
\quad(\mathbf{n}=\mathbf{1 5 8})\end{array}$ & $\begin{array}{c}\text { WMC severe } \\
\quad(\mathbf{n}=\mathbf{1 0 1})\end{array}$ & $\begin{array}{l}P \text { value } \\
\text { (trend) }\end{array}$ \\
\hline CPB time, min & $178.4 \pm 57.1$ & $179.4 \pm 59.5$ & $170.9 \pm 43.1$ & $189.2 \pm 71.0$ & .254 \\
\hline Myocardial ischemia, min & $79.8 \pm 39.0$ & $83.5 \pm 52.7$ & $75.7 \pm 30.9$ & $82.7 \pm 33.7$ & .085 \\
\hline Minimum tympanic temperature, ${ }^{\circ} \mathrm{C}$ & $21.4 \pm 1.8$ & $21.7 \pm 1.8$ & $21.5 \pm 1.8$ & $21.1 \pm 1.6$ & $.002 *$ \\
\hline Minimum rectal temperature, ${ }^{\circ} \mathrm{C}$ & $26.1 \pm 2.1$ & $26.1 \pm 2.0$ & $26.1 \pm 2.1$ & $26.2 \pm 2.2$ & .170 \\
\hline ACP time, $\min$ & $95.9 \pm 28.9$ & $90.4 \pm 24.0$ & $96.6 \pm 29.0$ & $100.4 \pm 32.3$ & $.002 *$ \\
\hline Circulatory arrest of lower body, min & $39.8 \pm 14.2$ & $38.9 \pm 13.9$ & $39.3 \pm 13.6$ & $41.5 \pm 15.5$ & .774 \\
\hline Concomitant CABG & $109(30.4)$ & $29(29.0)$ & $47(29.8)$ & $33(32.7)$ & .571 \\
\hline Aortic root replacement & $18(5.0)$ & $8(8.0)$ & $8(5.1)$ & $2(2.0)$ & .128 \\
\hline Aortic valve replacement & $17(4.7)$ & $4(4.0)$ & $9(5.7)$ & $4(4.0)$ & .751 \\
\hline Elephant trunk insertion & $74(20.6)$ & $23(23.0)$ & $28(17.7)$ & $23(22.8)$ & .767 \\
\hline Other procedures & $22(6.1)$ & $5(5.0)$ & $7(4.4)$ & $10(9.9)$ & .198 \\
\hline 30-d mortality & $5(1.4)$ & $2(2.0)$ & $1(0.63)$ & $2(2.0)$ & .993 \\
\hline Hospital mortality & $10(2.8)$ & $4(4.0)$ & $3(1.9)$ & $3(3.0)$ & 660 \\
\hline 1-y mortality & $27(7.9)$ & $5(5.1)$ & $8(5.4)$ & $14(14.7)$ & $.014^{*}$ \\
\hline Permanent neurologic deficits & $8(2.2)$ & $0(0)$ & $2(1.3)$ & $6(5.9)$ & $.004^{*}$ \\
\hline Transient neurologic deficits & $28(7.8)$ & $4(4.0)$ & $9(5.7)$ & $15(14.9)$ & $.004^{*}$ \\
\hline Deep sternal wound infection & $6(1.7)$ & $3(3.0)$ & $2(1.3)$ & $1(1.0)$ & .267 \\
\hline Postoperative AF & $112(31.2)$ & $24(24.0)$ & $50(31.7)$ & $38(37.6)$ & $.037^{*}$ \\
\hline Pneumonia & $23(6.4)$ & $5(5.0)$ & $7(4.4)$ & $11(10.9)$ & .090 \\
\hline Hoarseness & $59(16.4)$ & $19(19.0)$ & $23(14.6)$ & $17(16.8)$ & .680 \\
\hline Prolonged ventilation, $>48 \mathrm{~h}$ & $41(11.5)$ & $10(10.0)$ & $17(10.8)$ & $14(14.7)$ & .374 \\
\hline Tracheostomy & $20(5.6)$ & $6(6.0)$ & $8(5.1)$ & $6(5.9)$ & .986 \\
\hline Renal failure & $18(5.0)$ & $4(4.0)$ & $6(3.8)$ & $8(7.9)$ & .202 \\
\hline Length of hospital stay, $d$ & $21.0(16.0-29.0)$ & $20.0(15.0-26.3)$ & $21.0(16.0-28.0)$ & $22.0(17.0-32.0)$ & .509 \\
\hline Discharge to home & $305(87.4)$ & $86(89.6)$ & $136(87.7)$ & $83(84.7)$ & .304 \\
\hline
\end{tabular}

The $P$ values are for linear trend across the groups that were stratified by severity of white matter changes. $W M C s$, White matter changes; $C P B$, cardiopulmonary bypass; $A C P$, antegrade selective cerebral perfusion; $C A B G$, coronary artery bypass grafting; $A F$, atrial fibrillation. $* P<.05$.

$5.7 \%$, and severe: $14.9 \%, P=.004)$. Except for postoperative atrial fibrillation (mild: $24.0 \%$, moderate: $31.7 \%$, and severe: $37.6 \%, P=.037)$, other postoperative complications (deep sternal wound infection, pneumonia, hoarseness, prolonged ventilation, tracheostomy, and renal failure) showed no significant correlation with increasing severity of WMC. There were no significant differences in duration of hospital stay between patients who discharged home, according to WMC severity.

\section{Risk Analysis of Adverse Neurologic Outcomes}

The univariate analysis suggests that atherothrombotic aorta, severe WMC grade, and longer CPB time are significant risk factors for PNDs. Multivariate analysis also demonstrated that increasing severity of WMC is significant risk factor for PNDs (odds ratio [OR], 5.77; 95\% confidence interval $[\mathrm{CI}], 1.58-38.4, P=.005)$, as well as for atherothrombotic aorta $(\mathrm{OR}, 7.01 ; 95 \% \mathrm{CI}, 1.25-36.6$,
$P=.029)$ and CPB time (OR, 1.01; 95\% CI, 1.00-1.02, $P=.014$ ) (Table 3). In terms of TNDs, univariate analysis showed that atherothrombotic aorta, WMC grade, and carotid artery stenosis were significant risk factors of TNDs. Multivariate analysis demonstrated that the severity of WMC (OR, 2.46; 95\% CI, 1.45-4.37; $P<.001)$ was significant risk factor of TNDs (Table 4). Although statistically insignificant, atherothrombotic aorta $(\mathrm{OR}, 2.05 ; 95 \% \mathrm{CI}$, 0.97-6.37, $P=.056$ ) and carotid artery stenosis (OR, 2.14; $95 \% \mathrm{CI}, 0.88-4.90, P=.092$ ) trended toward being risk factors for TNDs.

\section{DISCUSSION}

Preoperative risk analysis has become even more crucial in elective surgery due to the increasing number of elderly surgical candidates for total arch replacement. ${ }^{1}$ Surgical repair should be indicated if the risk of rupture exceeds the risk of surgery. Our previous study had demonstrated 
TABLE 3. Univariate and multivariate analysis of PNDs

\begin{tabular}{|c|c|c|c|c|}
\hline Variables & $\frac{\text { Univariate }}{\text { OR }(95 \% \text { CI })}$ & $P$ value & $\frac{\text { Multivariate }}{\text { OR }(95 \% \text { CI })}$ & $P$ value \\
\hline Age, y & $1.03(0.96-1.14)$ & .484 & & \\
\hline Female & $1.97(0.46-8.41)$ & .377 & & \\
\hline Hypertension & - & .151 & & \\
\hline Dyslipidemia & $1.54(0.38-6.27)$ & .546 & & \\
\hline Diabetes mellitus & $3.45(0.80-14.9)$ & .121 & & \\
\hline Smoking & $0.58(0.14-2.48)$ & .476 & & \\
\hline Chronic dissection & - & .077 & & \\
\hline Previous aortic surgery & $0.51(0.06-4.23)$ & .508 & & \\
\hline Preoperative AF & $3.57(0.69-18.5)$ & .174 & & \\
\hline Chronic lung disease & $0.29(0.04-2.38)$ & .184 & & \\
\hline $\mathrm{eGFR}, \mathrm{mL} / \mathrm{min} / 1.73 \mathrm{~m}^{2}$ & $0.97(0.94-1.00)$ & .087 & & \\
\hline Atherothrombotic aorta & $5.42(1.24-23.6)$ & $.042 *$ & $7.01(1.25-36.6)$ & $.029 *$ \\
\hline Ischemic heart disease & $1.14(0.27-4.85)$ & .860 & & \\
\hline White matter change (/grade) & $6.14(1.78-38.6)$ & $.002 *$ & $5.77(1.58-38.4)$ & $.005^{*}$ \\
\hline Carotid artery stenosis & $0.92(0.11-7.68)$ & .941 & & \\
\hline Intracranial artery stenosis & $1.42(0.17-11.9)$ & .755 & & \\
\hline Incomplete circle of Willis & $1.30(0.29-8.95)$ & .747 & & \\
\hline Neurologic dysfunction & $3.44(0.40-29.9)$ & .329 & & \\
\hline Previous stroke & $2.22(0.55-9.04)$ & .271 & & \\
\hline CPB time, $\min$ & $1.01(1.00-1.02)$ & $.004 *$ & $1.01(1.00-1.02)$ & $.014^{*}$ \\
\hline Minimum tympanic temperature, ${ }^{\circ} \mathrm{C}$ & $0.94(0.64-1.36)$ & .755 & & \\
\hline ACP time, min & $0.99(0.97-1.02)$ & .662 & & \\
\hline Lower body circulatory arrest, min & $1.04(0.98-1.09)$ & .180 & & \\
\hline Concomitant CABG & $1.39(0.33-5.91)$ & .663 & & \\
\hline
\end{tabular}

$O R$, Odds ratio; $C I$, confidence interval; $A F$, atrial fibrillation; $e G F R$, estimated glomerular filtration rate; $C P B$, cardiopulmonary bypass; $A C P$, antegrade selective cerebral perfusion; $C A B G$, coronary artery bypass grafting. ${ }^{*} P<.05$.

that preoperative comorbidities such as chronic kidney disease and chronic obstructive pulmonary disease had negative prognostic implications for patients undergoing elective total arch replacement. ${ }^{17-19}$ Our previous report also identified sarcopenia as a core concept of frailty that may also have negative prognostic implications in these patients. ${ }^{19}$ Particularly in elderly patients, PNDs were the most significant complication, given their contribution to both late and early outcomes. In this study, our current procedure resulted in an improvement of the incidence of PNDs $(2.2 \%)$ and TNDs $(7.8 \%) .{ }^{3,16}$ However, the present study also suggests that WMC (defined by the Fazekas visual scale) may be a significant risk factor for neurologic dysfunction (graphical abstract), as similarly demonstrated by previous reports using the Scheltens scale. ${ }^{11,20}$

The Scheltens scale has a greater range than the Fazekas visual scale, has been found to better differentiate between groups, and may provide insight into WMC and cognition. ${ }^{21,22}$ In contrast, the Fazekas visual scale is one of the most appropriate for defining different WMC groups and is simple to assess. No group differences were detected in terms of neurologic symptoms. ${ }^{14}$ For this reason, we adopted the Fazekas visual scale in this follow-up study as opposed to the Scheltens scale. The relationship between these 2 scales has been demonstrated. ${ }^{14,15}$ The results of the high diagnostic coincidence of WMC between a cardiothoracic surgeon and a radiologist suggest that the Fazekas visual scale may be a more suitable scale for a cardiothoracic surgeon seeking to assess preoperative risk.

This study found that the incidence of adverse neurologic outcomes, including PNDs and TNDs, increased significantly according to WMC severity. In particular, patients with severe WMC had a markedly greater incidence of PNDs and TNDs. However, patients with severe WMC were typically older in age and had a greater number of comorbidities because WMC are age-related lesions. 
TABLE 4. Univariate and multivariate analysis of TNDs

\begin{tabular}{|c|c|c|c|c|}
\hline Variables & $\begin{array}{c}\text { Univariate } \\
\text { OR }(95 \% \text { CI })\end{array}$ & $P$ value & $\begin{array}{c}\text { Multivariate } \\
\text { OR }(95 \% \text { CI })\end{array}$ & $P$ value \\
\hline Age, $y$ & $1.03(0.99-1.09)$ & .186 & & \\
\hline Female & $1.32(0.56-3.11)$ & .534 & & \\
\hline Hypertension & $0.60(0.21-1.66)$ & .345 & & \\
\hline Dyslipidemia & $1.16(0.53-2.53)$ & .711 & & \\
\hline Diabetes mellitus & $0.40(0.09-1.75)$ & .172 & & \\
\hline Smoking & $0.52(0.23-1.14)$ & .112 & & \\
\hline Chronic dissection & $1.31(0.51-3.38)$ & .583 & & \\
\hline Previous aortic surgery & $0.78(0.29-2.13)$ & .623 & & \\
\hline Preoperative AF & $1.25(0.36-4.39)$ & .734 & & \\
\hline Chronic lung disease & $0.98(0.43-2.23)$ & .958 & & \\
\hline $\mathrm{eGFR}, \mathrm{mL} / \mathrm{min} / 1.73 \mathrm{~m}^{2}$ & $0.99(0.97-1.01)$ & .162 & & \\
\hline Atherothrombotic aorta & $4.01(1.63-9.89)$ & $.005^{*}$ & $2.59(0.97-6.37)$ & .056 \\
\hline Ischemic heart disease & $1.25(0.57-2.76)$ & .586 & & \\
\hline White matter change (/grade) & $2.41(1.26-4.61)$ & $.009^{*}$ & $2.46(1.45-4.37)$ & $<.001^{*}$ \\
\hline Carotid artery stenosis & $3.55(1.50-8.39)$ & $.007 *$ & $2.14(0.88-4.90)$ & .092 \\
\hline Intracranial artery stenosis & $2.35(0.83-6.67)$ & .134 & & \\
\hline Incomplete circle of Willis & $1.56(0.71-3.45)$ & .280 & & \\
\hline Neurologic dysfunction & $0.84(0.11-6.62)$ & .864 & & \\
\hline Previous stroke & $1.71(0.78-3.74)$ & .187 & & \\
\hline CPB time, min & $1.01(1.00-1.01)$ & .083 & & \\
\hline Minimum tympanic temperature, ${ }^{\circ} \mathrm{C}$ & $1.00(0.80 \pm 1.24)$ & .978 & & \\
\hline ACP time, $\min$ & $1.00(0.99 \pm 1.01)$ & .835 & & \\
\hline Lower body circulatory arrest, min & $0.99(0.96 \pm 1.01)$ & .278 & & \\
\hline Concomitant CABG & $1.09(0.48 \pm 2.50)$ & .832 & & \\
\hline
\end{tabular}

$O R$, Odds ratio; $C I$, confidence interval; $A F$, atrial fibrillation; $e G F R$, estimated glomerular filtration rate; $C P B$, cardiopulmonary bypass; $A C P$, antegrade selective cerebral perfusion; $C A B G$, coronary artery bypass grafting. $* P<.05$.

Although the severe WMC group had a greater European System for Cardiac Operative Risk Evaluation II and Japan score for mortality, the early mortality rate was similar across the 3 groups. In addition, we conducted multivariate logistic regression analysis to establish whether WMC severity was a significant risk factor for PNDs and TNDs. These results were acceptable compared with our previous report. ${ }^{10,11}$ Although atherothrombotic aorta was detected as a significant risk factor of adverse neurologic outcomes, there were no significant differences across each WMC severity. Therefore, we believe that WMC severity and atherothrombotic aorta should be used as different risk factors for adverse neurologic outcomes. The ACP time and minimum tympanic temperature were not risk factors for adverse neurologic outcomes in the present study, although there were significant differences among the 3 groups. The longer ACP time implied that the more severe WMC patients had, the more time it took to reconstruct arch vessels due to more complicated background. The lower temperatures reflect an intentionally longer cooling time to prevent adverse neurologic outcomes in specific patients. However, the results showed that the WMC severity was beyond the protective effect of lower temperature. Given that an incomplete circle of Willis and intracranial artery stenosis were not risk factors for adverse neurologic outcomes, our ACP strategy using 3 cannulae could be applied safely for patients with anomalies of the circle of Willis. However, further analysis is required to determine optimal methods of brain protection to reduce adverse neurological complications in patients with severe WMC.

Endovascular treatment or hybrid arch repair are alternative options for aortic arch aneurysms in high-risk patients. However, a recent study suggests that the incidence of intraoperative stroke is greater in these procedures. ${ }^{23}$ These results show that total arch replacement remains the gold standard for patients with lower grade of WMC, in terms stroke prevention. There may be some advantages in 

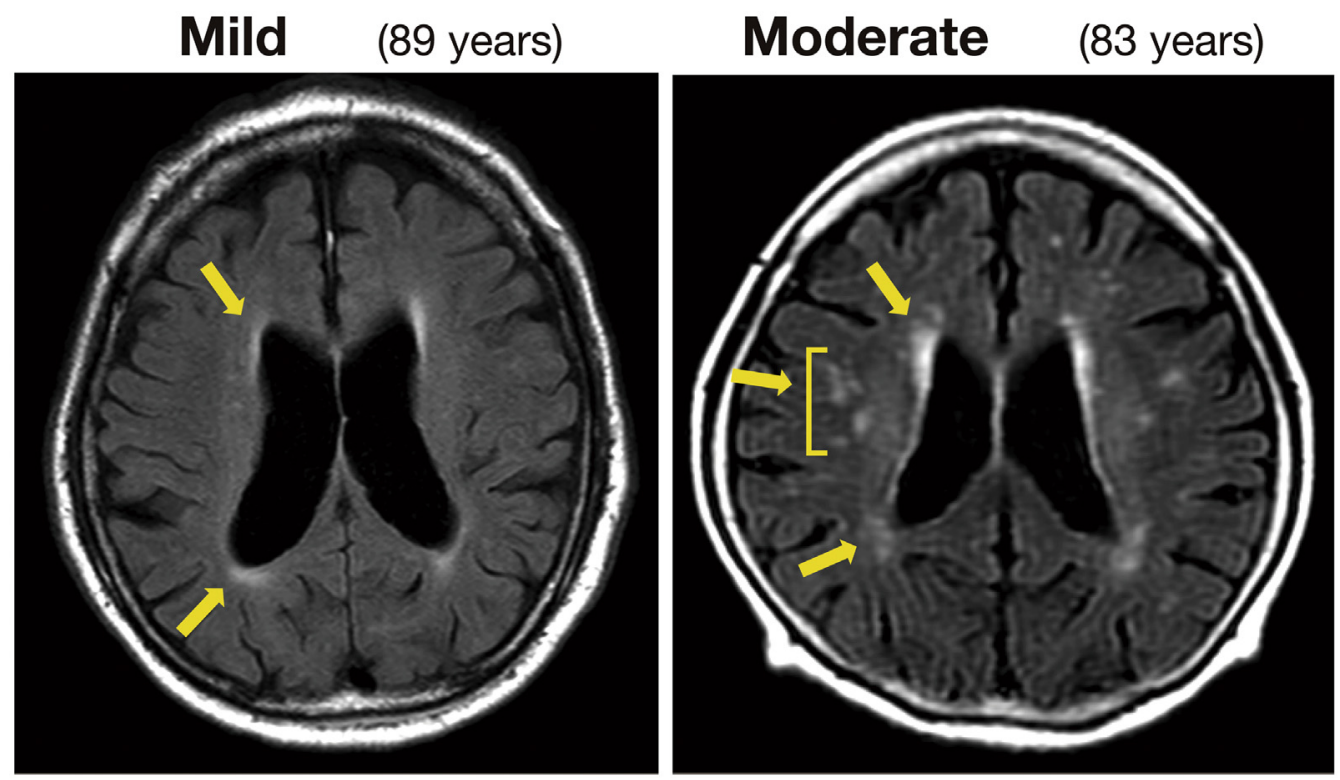

A

Severe

B (83 years)

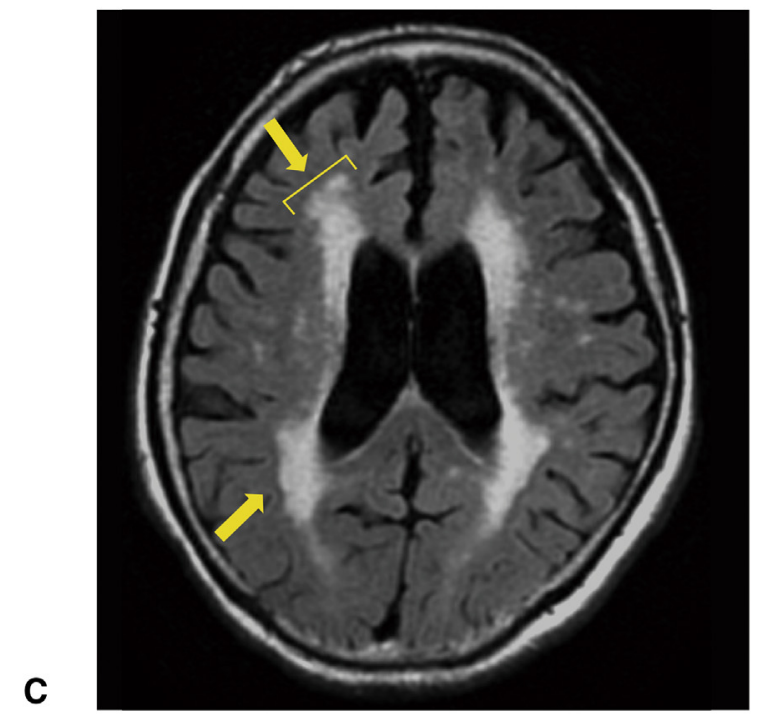

FIGURE 1. Magnetic resonance images of mild (A), moderate (B), and severe (C) white matter changes on the Fazekas visual scale. The arrows indicate the white matter changes.

avoidance of CPB and circulatory arrest in patients with severe WMC seeking endovascular treatment.

There were several limitations to our study. First, our study was retrospective. We did not have data about other scales of WMC and frailty, including quality of life. Second, reflecting the age-related change, the severe WMC group included patients with more complications. Although we conducted multivariate logistic regression analysis, several selection biases remained. Third, we did not have data regarding the relationship between WMC and adverse neurologic outcomes in other brain-protection strategies. Fourth, there were interobserver differences in diagnosing
WMC severity. Despite these limitations, this study demonstrated that detecting patients with severe WMC had clinical significance. We believe that the agreement for diagnosing severe WMC $(\kappa=0.86)$ was satisfactory.

\section{CONCLUSIONS}

WMCs, defined by the Fazekas visual scale on preoperative MRI, are significantly associated with adverse postoperative neurologic outcomes following total arch replacement using ACP. Preoperative MRI should be considered for patients who receiving elective total arch replacement. 


\section{Webcast}

You can watch a Webcast of this AATS meeting presentation by going to: https://aats.blob.core.windows.net/ media/18AO/26-br-1345-ikeno-v2.mp4.

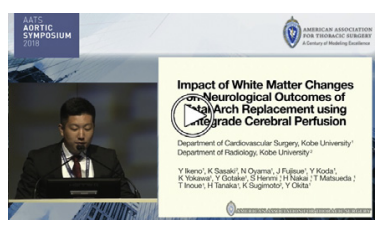

\section{Conflict of Interest Statement}

Authors have nothing to disclose with regard to commercial support

\section{References}

1. Okita Y. Surgery for thoracic aortic disease in Japan: evolving strategies toward the growing enemies. Gen Thorac Cardiovasc Surg. 2015;63:185-96.

2. Committee for Scientific Affairs, The Japanese Association for Thoracic Surgery, Masuda M, Kuwano H, Okumura M, Amano J, Arai H, Endo S, et al. Thoracic and cardiovascular surgery in Japan during 2012: annual report by the Japanese Association for Thoracic Surgery. Gen Thorac Cardiovasc Surg. 2014;62: 734-64.

3. Okita Y, Okada K, Omura A, Kano H, Minami H, Inoue T, et al. Total arch replacement using antegrade cerebral perfusion. J Thorac Cardiovasc Surg. 2013;145(3 suppl):S63-71.

4. Urbanski PP, Lenos A, Lindemann Y, Weigang E, Zacher M, Diegeler A. Carotid artery cannulation in aortic surgery. J Thorac Cardiovasc Surg. 2006;132: 1398-403.

5. Shijo T, Kuratani T, Torikai K, Shimamura K, Sakamoto T, Kudo T, et al. Thoracic endovascular aortic repair for degenerative distal arch aneurysm can be used as a standard procedure in high-risk patients. Eur J Cardiothorac Surg. 2016;50:257-63.

6. Shibata M, Ohtani R, Ihara M, Tomimoto H. White matter lesions and glial activation in a novel mouse model of chronic cerebral hypoperfusion. Stroke. 2004; 35:2598-603.

7. Van Der Flier WM, van Straaten EC, Barkhof F, Verdelho A, Madureira S, Pantoni L, et al. Small vessel disease and general cognitive function in nondisabled elderly. Stroke. 2005;36:2116-20.

8. Inzitari D, Pracucci G, Poggesi A, Carlucci G, Barkhof F, Chabriat H, et al. Changes in white matter as determinant of global functional decline in older independent outpatients: 3-year follow-up of LADIS (leukoaraiosis and disability) study cohort. BMJ. 2009;339:b2477.

9. Scheltens P, Barkhof F, Leys D, Pruvo JP, Nauta JJ, Vermersch P, et al. A semiquantative rating scale for the assessment of signal hyperintensities on magnetic resonance imaging. J Neurol Sci. 1993;114:7-12.
10. Okada K, Omura A, Kano H, Inoue T, Oka T, Minami H, et al. Effect of atherothrombotic aorta on outcomes of total aortic arch replacement. J Thorac Cardiovasc Surg. 2013;145:984-91.

11. Morimoto N, Okada K, Uotani K, Kanda F, Okita Y. Leukoaraiosis and hippocampal atrophy predict neurologic outcome in patients who undergo total aortic arch replacement. Ann Thorac Surg. 2009;88:476-81.

12. Fazekas F, Chawluk JB, Alavi A, Hurtig HI, Zimmerman RA. MR signal abnormalities at $1.5 \mathrm{~T}$ in Alzheimer's dementia and normal aging. AJR Am J Roentgenol. 1987;149:351-6.

13. Madureira S, Verdelho A, Ferro J, Basile AM, Chabriat H, Erkinjuntti T, et al Development of a neuropsychological battery for the Leukoaraiosis and Disability in the Elderly Study (LADIS): Experience and baseline data. Neuroepidemiology. 2006;27:101-16.

14. van Straaten EC, Fazekas F, Rostrup E, Scheltens P, Schmidt R, Pantoni L, et al Impact of white matter hyperintensities scoring method on correlations with clinical data: the LADIS study. Stroke. 2006;37:836-40.

15. Inzitari D, Simoni M, Pracucci G, Poggesi A, Basile AM, Chabriat H, et al Risk of rapid global functional decline in elderly patients with severe cerebral age-related white matter changes: the LADIS study. Arch Intern Med. 2007; $167: 81-8$.

16. Okada K, Omura A, Kano H, Sakamoto T, Tanaka A, Inoue T, et al. Recent advancements of total aortic arch replacement. J Thorac Cardiovasc Surg. 2012 $144: 139-45$.

17. Okada K, Omura A, Kano H, Nakai H, Miyahara S, Minami H, et al. Outcome of elective total aortic arch replacement in patients with non-dialysis-dependent renal insufficiency stratified by estimated glomerular filtration rate. J Thorac Cardiovasc Surg. 2014;147:966-72.e962.

18. Miyahara S, Nakai H, Izawa N, Yamanaka K, Sakamoto T, Nomura Y, et al. Influences of chronic obstructive pulmonary disease on outcomes of total arch replacement. Ann Thorac Surg. 2015;99:72-8.

19. Ikeno Y, Koide Y, Abe N, Matsueda T, Izawa N, Yamazato T, et al. Impact of sarcopenia on the outcomes of elective total arch replacement in the elderly. Eur J Cardiothorac Surg. 2017;51:1135-41.

20. Lin R, Svensson L, Gupta R, Lytle B, Krieger D. Chronic ischemic cerebral white matter disease is a risk factor for nonfocal neurologic injury after total aortic arch replacement. J Thorac Cardiovasc Surg. 2007;133:1059-65.

21. Gunning-Dixon FM, Raz N. The cognitive correlates of white matter abnormalities in normal aging: a quantitative review. Neuropsychology. 2000;14: 224-32.

22. Poggesi A, Pantoni L, Inzitari D, Fazekas F, Ferro J, O’Brien J, et al. 2001-2011: a decade of the LADIS (Leukoaraiosis and Disability) study: what have we learned about white matter changes and small-vessel disease? Cerebrovasc Dis. 2011;32:577-88

23. Hiraoka A, Chikazawa G, Totsugawa T, Tamura K, Ishida A, Sakaguchi T, et al Objective analysis of midterm outcomes of conventional and hybrid aortic arch repair by propensity-score matching. J Thorac Cardiovasc Surg. 2017;154: 100-6.e101.

Key Words: aortic arch surgery, total arch replacement, perioperative care, magnetic resonance image, postoperative stroke 


\section{Periventricular Hyperintensities (PVH 0-6)}

\begin{tabular}{rll}
\hline caps. occipital & $0 / 1 / 2$ & $0=$ absent \\
frontal & $0 / 1 / 2$ & $1=\leq 5 \mathrm{~mm}$ \\
bands lat ventricles & $0 / 1 / 2$ & $2=>5 \mathrm{~mm}$ and $<10 \mathrm{~mm}$
\end{tabular}

White matter hyperintensities (WMH 0-24)

\begin{tabular}{lll}
\hline Frontal & $0 / 1 / 2 / 3 / 4 / 5 / 6$ & $0=\mathrm{na}$ \\
Parietal & $0 / 1 / 2 / 3 / 4 / 5 / 6$ & $1=<3 \mathrm{~mm}, \mathrm{n} \leq 5$ \\
Occipital & $0 / 1 / 2 / 3 / 4 / 5 / 6$ & $2=<3 \mathrm{~mm}, \mathrm{n}>6$ \\
Temporal & $0 / 1 / 2 / 3 / 4 / 5 / 6$ & $3=4-10 \mathrm{~mm}, \mathrm{n} \leq 5$ \\
& & $4=4 \mathrm{~mm}, \mathrm{n}>6$ \\
& $5=>11 \mathrm{~mm}, \mathrm{n}>1$ \\
& $6=$ confluent
\end{tabular}

Total Leukoaraiosis score $(0-30)=$ PVH + WMH

FIGURE E1. Scheltens scale (Leukoaraiosis score 0-30). ${ }^{9} P V H$, Periventricular hyperintensities; $W M H$, white matter hyperintensities. 